I Universidade Federal Fluminense (UFF), Departamento de Sociologia,

Niterói, RJ, Brasil

carmen.ppgsd@gmail.com

https://orcid.org/oooo-0002-0030-2549

Carmen Felgueiras'

\title{
PARA UM PENSAMENTO SOCIAL LATINO-AMERICANO? RETRATOS DA MEMORIALÍSTICA LATINO-AMERICANA
}

Miceli, Sergio \& Myers, Jorge (orgs.). (2019).

Retratos latino-americanos. A recordação letrada de

intelectuais e artistas do século XX. São Paulo:

Edições Sesc São Paulo.

A sequência de citações do Prólogo desde a aliteração proposta para o título, o mesmo da coletânea de poemas de Paul Éluard, passando pela epígrafe de Cabrera Infante, até o subtítulo, que termina com a pergunta do poeta surrealista francês Robert Desnos, "puis-je deféndre ma mémoire contre l'oubli?" dá o tom dessa coletânea de textos de latino-americanos do século XXI, I 8 brasileiros e I 9 hispano-americanos. Compõe-na de nada menos que 37 autores, entre antropólogos e sociólogos, historiadores e críticos literários, empenhados em interpretar artistas e intelectuais do século XX que deram feições particulares a um tema universal, o esforço contra o esquecimento, o "dur désir de durer".

Assim, em alentada introdução, Sergio Miceli e Jorge Myers procuram conduzir o leitor ao longo das 500 páginas de Retratos latino-americanos. A recordação letrada de intelectuais e artistas do século XX. Começam por situar conceitualmente o gênero memorialístico e suas subdivisões, como diários, autobiografias, memórias, além de outras formas periautográficas como correspondências e biografias, tratando, enfim, das múltiplas formas de expressão escrita, pelas quais se manifestou uma variedade de indivíduos em contextos históricos e sociais es pecíficos sobre a questão universal da permanência, da duração. Qual o sentido dessas divisões? Desde logo, cada qual pode ser considerada índice de uma relação específica de seu autor com o texto e com tudo aquilo que o circunscreve. Estão em jogo desde protocolos da escritura à intencionalida- 
de do escritor. Ora o acento é a própria subjetividade, ora um testemunho pessoal feito seja para justificar atos ou para intervir na política de seu tempo em uma conjugação de lembrança do passado e imaginação do futuro. É importante, contudo, observar desde já que, na visão normativa dos organizadores, essa diversidade formal dos objetos não deveria ser acompanhada por uma igual diversidade de pressupostos interpretativos, contrariando, portanto, a proposta de pluralidade embutida na expressão "retratos". Para ambos, chegar às motivações e intenções dessas escritas não seria uma operação a ser atingida pela via exclusiva do contato com os textos, mas exigiria o conhecimento prévio dos contextos histórico-sociais em que foram produzidos. Nesse sentido, Miceli e Myers, ao pretender situar a escritura memorialística como uma prática que se subordina "ao campo geral das práticas sociais que articula a vida cultural e intelectual contemporânea" ${ }^{I}$ acabam generalizando uma posição que é de apenas parte dos autores da coletânea e transferindo ao leitor a tarefa de perceber as diferenças e mesmo o dissenso entre eles.

Nas seções "Memorialística latinoamericana: uma tradição própria" e "Modalidades da memorialística hispano-americanas" é feito um inventário tão extenso quanto minucioso dessa tradição que desde logo revela os critérios de seleção dos capítulos do livro. A categorização se inicia pela via cronológica, pela autobiografia como escrito político da era das revoluções de inde- pendência, chegando à autobiografia vinculada à cidade e à vida moderna. $\mathrm{O}$ movimento diacrônico dos estilos e subgêneros não exclui, entretanto, a sincronia de motivações e efeitos, verificando-se, por exemplo, a permanência do sentido político de muitas autobiografias do período mais recente. Transformações na sociedade hispano-americana do século XX teriam implicado, segundo os autores, "um leque novo de possibilidades para a memorialística", que, de um modo geral, oscilou entre as temáticas da esfera pública - desde o já mencionado tema da cidade, da ampliação da vida artística e intelectual e das questões profissionais -, quando a partir dos testemunhos pessoais chegar-se-ia a uma "história externa de uma formação intelectual", e as temáticas da vida privada, nas quais a subjetividade ganharia relevo, fosse no tratamento das formas de expressão da intimidade, como a correspondência, fosse no tratamento da infância e do amor, presente nas autobiografias, nas memórias e nos diários.

Na seção sobre a memorialística brasileira do século XX é possível inferir que seu desenvolvimento seguiu um padrão similar ao de suas congêneres hispano-americanas, visto que a seleção de autores e temáticas se encaixa nos mesmos critérios que presidiram a escolha dos artigos dos hispânicos. Apenas o capítulo final, "Traumas do viver", é exclusivamente composto de textos de brasileiros sobre brasileiros, o que, evidentemente, não significa em absoluto a ausência de trabalhos publicados de autores 
hispânicos sobre os temas da loucura, do suicídio e da prisão.

O texto colocado como epílogo do livro, "A autobiografia como objeto do discurso intelectual", trata da crítica literária argentina, em particular da produção do crítico Adolfo Prieto, autor de La literatura autobiográfica argentina. A análise de Alejandro Blanco e Luiz Carlos Jackson é feita com o intuito de demonstrar as condicionantes sociais e políticas da vida literária e, nesse sentido, se atém a explicar a escolha de Prieto pela crítica literária em função daquelas condicionantes, sem entrar propriamente na investigação dos critérios de composição de sua obra. Essa pers pectiva é inteiramente diferente da que encontramos nos textos de Ricardo Benzaquen, André Botelho, Leopoldo Waizbort, Regina Crespo, Francisco Rodrigues Cascante e Rafael Rojas, para citar apenas alguns, nos quais as pesquisas documentais e as orientações teóricas para a análise textual são recortadas e articuladas de modos diversos e irredutíveis entre si.

$\mathrm{Na}$ esteira destes comentários seguem-se alguns outros. O primeiro, de fatura complexa, diz respeito aos critérios de importância do texto e do seu significado. Duas posições, até certo ponto contrastantes, têm marcado o debate no campo do pensamento social. Uma delas afirma que tais critérios devem ser buscados fora do texto, em um contexto concebido em sua objetividade e do qual o texto participa como documento. A outra, na articulação do texto com um contexto construído, quer pelo autor, quer por seu intérprete, e dotado de capa- cidade de interpelação singular desse próprio contexto. Neste último sentido, por exemplo, a afirmação de que o diário pessoal de Gamboa "importa na medida em que oferece um panorama amplo e detalhado da vida política e literária do México" deveria estar seguida do complemento "na visão de Gamboa", pois trata-se de um recorte específico, de uma reconstrução contextual realizada por esse autor. Caberia, então, ao intérprete entender os princípios pelos quais artistas e intelectuais fizeram seleções e exclusões para a composição de suas recordações letradas. Também no caso dos relatos singulares da vida erótica de Blanco Bombona importam tanto as suas condições objetivas de possibilidade quanto seu papel ativo, ou os efeitos que quis produzir por meio do seu diálogo específico com tradições literárias que têm no erotismo seu tema central e que, por sua vez, conformam tanto instituições literárias quanto subjetividades.

O segundo diz respeito à relação de afinidade entre os subgêneros da memorialística e os contextos históricos nos quais foram produzidos. A partir desse suposto foi possível aos organizadores perceber que a autobiografia cívica, a autobiografia profissional, relatos sobre a atuação pública, assim como a literatura de denúncia testemunhal, proliferaram nas épocas de guerra civil e de ditadura. Nada impediria, contudo, que a partir desses testemunhos se tivesse por objetivo destacar as formas pelas quais os autores organizam a totalidade autobiográfica em função de elementos sub- 
jetivos, independentemente do fato de que essas ênfases subjetivas possam ou não ser reveladoras de padrões societários mais amplos. Ou seja, uma obviedade a ser levada em conta aqui é que a proporção em que a quantidade de variáveis entra na explicação de uma totalidade é sempre em menor número das que a compõem.

Em terceiro lugar, convém discutir a relação necessária entre gêneros e subgêneros e temáticas que organizam o campo da memorialística. Como não foram os primeiros que orientaram a organização do livro, caberia perguntar como essas distinções aparecem nos autores e em seus intérpretes. Como podemos constatar pela organização da primeira seção "Recordações dos intelectuais a serviço da revolução", dos dez ensaios, apenas três são sobre autores brasileiros - Jorge Amado, Otávio de Faria e Fernando Gabeira e, desses, dois escrevem suas memórias. O excelente trabalho de pesquisa de Elide Rugai Bastos persegue as pistas da ausência deliberada de dados biográficos na pena de Otavio de Faria e lança mão de um conjunto eclético de notas de diários, entrevistas e correspondências para os reconstituir. Nesse sentido, constitui uma provocação da própria coletânea incitar o leitor a uma pesquisa dessa relação ao longo dos seus 37 artigos.

Por fim, cabe ponderar que o valor universal do desejo de duração e das práticas que o confirmam constitui uma característica do Ocidente moderno, associada à acumulação e à preservação. Entre elas está o colecionamento, do qual a própria coletânea em questão seria, por analogia, um exemplo. Se, como nos diz James Clifford (I988), essas práticas têm um papel constitutivo no processo de formação de determinadas subjetividades individuais e coletivas, Retratos latino-americanos teria um lugar importante na constituição daquilo que poderíamos chamar de "pensamento social latino-americano", pela afirmação de uma certa unidade de temáticas e questões na diversidade interpretativa de sua memorialística, com propósito claro de lhe conferir autenticidade e identidade. Como esclarecem Miceli e Myers, o livro parte da hipótese da especificidade da experiência memorialística latino-americana "como ação histórico-cultural, como intervenção concreta em um universo específico, temporal e geográfico, de significação social que por sua própria natureza [e por seu caráter enraizado em uma comunidade] só pode constituir-se num fato significante".

Além de seu valor intrínseco e pragmático, há também que considerar seu valor heurístico. Como é sabido, essa coletânea é parte do trabalho de uma ampla rede de pesquisadores de vários países e instituições, cuja produção já foi objeto de resenha publicada em Sociologia \& Antropologia 5/3 e constitui um estimulante desafio para que se conheça, pontualmente ou na íntegra, o seu objeto, o extenso mosaico da escrita memorialística latino-americana. Reconstituir os laços que possam levar a uma certa uni- 
dade possível, para além dos eixos temáticos propostos, quer incluindo outros temas, quer produzindo variações e cruzamentos entre eles, talvez seja o maior desses desafios.

Recebida em I3/09/2020 Aprovada em I 2/I 2/2020

Carmen Felgueiras é professora do Departamento de Sociologia e Metodologia das Ciências Sociais e do Programa de Pós-Graduação em Sociologia e Direito da Universidade Federal Fluminense (UFF). 
PARA UM PENSAMENTO SOCIAL LATINO-AMERICANO?

354

\section{NOTA}

I A ausência de indicação de página neste e nos demais trechos citados se deve ao fato de a autora da resenha ter feito em versão kindle a leitura da obra resenhada (NE).

\section{REFERÊNCIA BIBLIOGRÁFICA}

Clifford, James. (I988). The predicament of culture. Cambridge, Mass.: Harvard University Press. 